\title{
Literatura, História e as primeiras obras de Terry Eagleton
}

\author{
Literature, History and the first works of Terry \\ Eagleton
}

\author{
Daniel Puglia *
}

Resumo: Este artigo tem por objetivo apresentar algumas das ideias presentes nos primeiros livros do ensaísta e crítico literário britânico Terry Eagleton. A contribuição de tais ideias para a análise das relações entre literatura e história serve como parâmetro para a discussão de obras importantes da recente crítica literária materialista, como por exemplo, Marxism and literary criticism (1976) e Walter Benjamin, or towards a revolutionary criticism (1981).

Palavras-chave: Literatura e história, literatura e sociedade, crítica literária.

Abstract: This article intends to present some of the ideas in the first books of the British essayist and literary critic Terry Eagleton. The contribution of his ideas in the analysis of the relation between literature and history serves as a parameter for the discussion of important works in the field of recent materialistic literary criticism, such as Marxism and literary criticism (1976) and Walter Benjamin, or towards a revolutionary criticism (1981).

Keywords: Literature and history, literature and society, literary criticism.

${ }^{*}$ Professor da Universidade de São Paulo. 
o analisar alguns aspectos da obra do ensaísta inglês Terry Eagleton, podemos verificar o quanto ela pode contribuir para as discussões de todos os que se interessam pela relação entre literatura e história. Embora muitos de seus ensaios dialoguem com obras presentes no universo das literaturas em língua inglesa, sua abordagem e sua perspectiva podem auxiliar a interpretação de textos e contextos os mais diversos, pois estamos diante de um autor que procura resgatar uma longa tradição da crítica dialética: um procedimento investigativo sempre atento ao modo como as formas e os conteúdos iluminam diferentes conjunturas, em diversos momentos históricos.

Neste artigo, comentaremos alguns aspectos das primeiras obras de Eagleton, tendo sempre em mente nuances que viriam a aparecer em estudos posteriores do autor, revelando uma coerência até certo ponto surpreendente, uma vez que seus escritos cobrem praticamente as últimas cinco décadas dos debates críticos. Merece destaque também o modo como Eagleton mantém, desde o princípio, um diálogo constante com uma variada gama de escolas teóricas, sempre procurando inseri-las em contextos sócio-históricos e adotando uma concepção em que a divisão tradicional entre diferentes disciplinas é ultrapassada, buscando um intercâmbio verdadeiramente interdisciplinar. Como complemento e talvez consequência prática dessa conduta, em que ficam claras as dimensões políticas das escolhas teóricas, vale notar que Eagleton elabora um dos mais úteis esforços no campo do ensaio crítico e de intervenção: procura divulgar, difundir e explicar inúmeros aspectos das correntes críticas, bem como da interpretação cultural e literária, constituindo um poderoso recurso pedagógico com marcado interesse nos debates contemporâneos e o olhar formado na contracorrente das visões hegemônicas.

Um dos primeiros livros de Eagleton, Shakespeare and Society: Critical Studies in Shakespearean Drama (1967), é considerado por alguns comentadores como um trabalho em que a influência direta do materialismo histórico ainda é tênue, sendo muito mais relevantes os aspectos advindos diretamente do que seriam as nuances humanistas de Raymond Williams. Contudo, talvez aqui os comentadores confundam a proximidade estilística que, especificamente nesse livro, Eagleton apresenta em relação a Williams e, fazendo isso, exacerbam uma proximidade mais ilusória do que efetivamente presente na forma e no conteúdo do livro - além de não fazerem justiça à sofisticação de pensamento de Williams, incorrendo em mais uma das muitas simplificações que sua obra sofre nas mãos 
da crítica. De todo modo, a influência do materialismo de Williams pode ser visto de maneira indireta. Assim, mesmo sendo um trabalho inicial, Shakespeare and Society reflete algumas das discussões possíveis da dinâmica entre indivíduo e sociedade presentes na obra de Shakespeare, com a nota positiva de visitar em nova chave um assunto que é quase a personificação do cânone literário ocidental, infelizmente estudado nas universidades e nos salões da cultura muitas vezes mais como objeto de culto do que de efetivo conhecimento.

Já um segundo livro como The Body as Language (1970) documenta de modo muito mais interessante vetores críticos que posteriormente serão retomados com frequência. Para muitos dos que se surpreendem com as recentes discussões sobre religiosidade e fé na obra de Eagleton, esse livro poderia servir como uma advertência do quanto tal temática há muito faz parte de seu corpus de análise. Oriundo da classe trabalhadora, inglês de nascimento mas de origem irlandesa, Eagleton é um egresso da esquerda católica. Em certa medida, pode ser compreendido como um produto da força que a igreja progressista teve durante a década de sessenta, quando o marxismo e a teologia se encontraram em resposta a necessidades materiais urgentes e esperanças efetivas de transformação. Também surge nesse livro o interesse pelas discussões acerca do corpo, da tragédia e da terminologia lacaniana que irá ocorrer de modo acentuado em livros como Sweet Violence (2003), revelando uma linha de continuidade na obra de Eagleton que talvez mereça ser mais bem pesquisada.

Os ensaios que compõem o volume Exiles and Émigrés: Studies in Modern Literature (1970) constituem um importante espaço para a reflexão cuidada e atenta, enfocando as interações entre literatura, história e sociedade, mais precisamente sobre o fenômeno dos deslocamentos espaciais e físicos - mas também subjetivos - de uma série de escritores fundamentais para a literatura. A ênfase aqui recai sobretudo em emigrados ilustres, da virada do século dezenove e início do século vinte: Joseph Conrad, Henry James, T.S. Eliot, Ezra Pound, W.B. Yeats e James Joyce. Em maior ou menor grau, todos são analisados como testemunhas de um período de turbulência social e econômica, quando o império inglês se aproxima de seu fatal declínio. Na perspectiva de Eagleton, o testemunho de tais autores traz a marca daqueles que observam o contexto inglês com um olhar estrangeiro, o que serve muitas vezes para tomar o pulso da época e do lugar sob uma perspectiva de maior acuidade e abrangência. Como apontam alguns estudiosos, essa obra marca o período em que as teorias sobre 
o realismo desenvolvidas por Georg Lukács embasam muito do pensamento de Eagleton, embora já as complementando em diálogo profícuo com a visada teórica de Raymond Williams. Tendo como preocupação essencial a capacidade da apreensão da totalidade sócio-histórica na forma literária, o empenho de Eagleton é demonstrar o quanto tal apreensão passa a ser muito mais problemática a partir de meados do século dezenove - o que de certa maneira faz ver sob novo ângulo o próprio veredicto lukacsiano em relação às obras realistas, consideradas pelo teórico húngaro de modo muito mais positivo do que a obras modernistas. Uma das teses de Eagleton, retomada um pouco mais tarde em livros como Marxism and Literary Criticism (1976), propõe que a própria dinâmica social na passagem do século impunha novos desafios, tornando o diagnóstico totalizador preconizado por Lukács uma tarefa ainda mais difícil de ser levada a efeito.

Na trilha aberta por Exiles and Émigrés, de discussão de obras fundamentais não apenas para a literatura em língua inglesa mas também para a literatura mundial, o livro Myths of Power: A Marxist Study of the Brontës (1975) sinaliza uma inflexão mais acentuada em direção a uma abordagem explicitamente marxista, denotando também o influxo do estruturalismo de Althusser no universo crítico britânico, em geral, e em Eagleton, em particular. Até certo ponto, Myths of Power é a tentativa de aplicação prática de um receituário conceitual esboçado em Criticism and Ideology: A Study in Marxist Literary Theory (1976), ponto extremo da fase estruturalista de Eagleton. Com razão, este é considerado seu primeiro grande trabalho de teoria literária, debatendo alguns pressupostos de uma tradição marxista ortodoxa que via a literatura como reflexo mecânico e automático da sociedade, num determinismo bastante estreito e que deixava pouco espaço para a dialética. O ponto de partida de Eagleton é fazer a ideologia e não a realidade a matéria-prima da literatura: esta retrabalharia os materiais disponíveis no plano ideológico, produzindo um novo arranjo formal, constituindo assim a relativa autonomia da obra de arte em relação à economia e aos modos de produção. Embora excessivamente carregado com um jargão que pretende desenvolver uma ciência da literatura, a atenção à forma como princípio fundamental de análise aparece nesse livro como uma contribuição importante no caminho de um materialismo que não seja redutor e mecanicista. De todo modo, em Criticism and Ideology, Eagleton ainda não desenvolve uma discussão que mais tarde se tornaria central para sua contribuição efetiva aos estudos sobre crítica, literatura e ensino - a saber, o próprio questionamento acerca do 
conceito de literatura e da institucionalização feita em relação a esse conceito. Nesse livro, temos um ensaísta bastante preocupado com uma categoria rígida de "literatura" e da atividade crítica vista sob um enfoque de ciência com status definido. Por um lado, o livro abarca discussões importantes referentes à autonomia relativa da esfera literária, o que significa recusar a simples proposição de literatura vista como puro reflexo mecânico de impulsos histórico-culturais. Por outro lado, não tem a mesma acuidade, clareza ou capacidade de intervenção daquele que é visto como seu complemento: Marxism and Literary Criticism (1976).

Embora muitos o vejam como um mero complemento de Criticism and Ideology, padecendo das mesmas falhas deste, a leitura atenta pode revelar algo diferente: Marxism and Literary Criticism, um breve ensaio de apresentação e panorama históricos, na verdade é uma preciosidade no gênero de divulgação científica e popularização de conceitos para além dos muros da academia. Uma quantidade impressionante de autores e escolas são estudados, servindo ainda como um excelente texto introdutório sobre o materialismo histórico. Em vez de ser encarado de maneira derrisória, como uma simples cartilha para consumo fácil, esse ensaio pode ser apreciado como um dos pilares fundadores de dois aspectos na obra de Eagleton: por um lado, o diálogo com diversas abordagens críticas tendo o materialismo como baliza e, por outro, a notável capacidade de apresentar temas complexos de forma simples, mas jamais simplória. Na concepção do livro parece já estar uma lei de movimento que podemos perceber em outros pontos da obra que viria nas décadas seguintes: a teoria vista como instrumento de intervenção prática, alimentada pela realidade para cuja transformação deseja contribuir.

Infelizmente esse ensaio de divulgação e intervenção ainda é mal aproveitado para os estudos sobre literatura, cultura e suas relações com a sociedade. É interessante observar que o próprio Eagleton parece um tanto quanto reticente para avaliar os méritos do livro. No entanto, assinala corretamente que ele é fruto de uma atmosfera especial: a riqueza de um contexto em que os grupos de estudos aliavam pessoas da universidade com pessoas pertencentes a diferentes setores da sociedade. Essa conexão e esse intercâmbio talvez respondam, ao menos em parte, pela extraordinária capacidade que o pequeno livro tem de, sem jamais baratear seus conteúdos, despertar o interesse de um público bastante amplo. Nas palavras do próprio autor: 
[...] Marxismo e crítica literária foi comissionado para a série "Critical Idiom", que estava buscando ir além da metáfora e do ponto-e-vírgula e outros tópicos similares que já haviam sido exauridos. Eu estava na verdade reunindo materiais para Criticism and Ideology naquele momento, então ele foi um subproduto disso. Mas creio que aquilo realmente se tornou um padrão consciente mais tarde, no sentido de que descobri que gostava de popularizar ideias e pensava ter competência para fazê-lo. Marxismo e crítica literária foi o primeiro exemplo disso. A partir de então, tenho tido a tendência de intercalar obras mais difíceis e mais populares. (Eagleton e Beaumont, 2010: 160)

Essa tendência mencionada por Eagleton vai ao encontro de algo que podemos comprovar analisando o conjunto de sua obra. Na impressionante quantidade de livros, ensaios e resenhas produzidas pelo autor, o ímpeto de divulgação de temas teóricos complexos aparece sempre alicerçado num estilo de inconfundível limpidez, o que nem sempre é bem recebido por alguns setores do público universitário ou ainda é visto como excessivo pluralismo do autor, num gesto que acompanharia modas teóricas do momento com o intuito de simplificá-las ou torná-las palatáveis para o grande público. Mas aqui ocorre um grande mal-entendido, uma vez que essa postura de intervenção de Eagleton nada mais faz do que seguir um dos fundamentais procedimentos do materialismo histórico, ou seja, visitar os variados enfoques teóricos, sem dogmatismos ou reducionismos, para tentar aproveitar o que de útil ou mesmo de problemático tais enfoques trazem como ferramenta de diagnóstico e de intervenção social. Vale notar que muitas vezes as mais ferrenhas críticas em relação à abordagem de Eagleton vêm justamente de muitos que se colocam como guardiões de uma certa ortodoxia do materialismo histórico, guardiões estes que não raro jogam o pensamento dialético fora e seguem algumas poucas formulações de modo esquemático e redutor.

Para os que se interessam pelo encadeamento estabelecido entre literatura e história, um aspecto particularmente relevante aparece ilustrado em Marxism and Literary Criticism: a relação entre o ensaio e o contexto de sua produção e recepção. Embora seja um livro altamente conceitual, como apontado pelo próprio autor, seu aparecimento se justifica dentro de um ambiente em que as questões referentes a cultura, história e política estavam na ordem do dia. $\mathrm{Na}$ segunda metade da década de setenta, esse ainda era um eco de um período an- 
terior, em que o engajamento político e a intervenção estética caminhavam lado a lado. A conjuntura histórica seguinte viria amenizar tais tendências, uma vez que no início da década de oitenta os debates em torno das abordagens críticas iriam cada vez mais servir de caixa de ressonância para um período de marcado conservadorismo político. Num certo sentido, e especificamente dentro do campo teórico, a inação prática seria compensada por uma inflação de tendências e escolas interpretativas, preparando o terreno para o que viria a ser conhecido sob o amplo leque do chamado pós-modernismo. A postura crítica de Eagleton, no entanto, ganha um peso e um enfoque que serviriam para embasar muito de sua intervenção e investigação nas décadas seguintes. Em outras palavras, navegando nos mares revoltos da proliferação teórica, Eagleton vai saber aproveitar a profusão de novas tendências críticas para fazer uma leitura que privilegie o entendimento acerca do significado histórico e político do surgimento de tais tendências críticas. Sem aderir de modo irrefletido ou refutar de modo dogmático, sua conduta tentará explicar o processo social envolvido na construção desse grande mercado das interpretações críticas. Ou seja, como ele mesmo lembra: "[...] apesar de nunca ter sido um pluralista liberal, no sentido de tentar acomodar todas essas abordagens, sempre acreditei, pelo menos a partir do livro sobre Benjamin, em tentar ser aberto a outras abordagens. Assim, aquele era um precário ato de equilíbrio" (Eagleton e Beaumont, 2010: 179). Esse equilíbrio, essa forma de refletir sobre o que de novo surgia sem resvalar para a adesão pura e simples, pode também ser compreendido em outra reflexão do autor:

[...] Creio que poderíamos dizer que eu era anti-historicista no sentido de que queria evitar o relativismo histórico, mas era historicista no sentido de consultar o contexto histórico. As verdades são históricas no sentido de que são produzidas historicamente, mas não no sentido de que o que é verdadeiro só é verdadeiro em sua própria época. (Eagleton e Beaumont, 2010: 180)

Marxism and Literary Criticism, pela maneira que lida com tais questões, assinala um indício, sugerindo um ponto de virada na obra do autor. Essa inflexão ficaria ainda mais clara depois de Walter Benjamin, or Towards a Revolutionary Criticism (1981).

Possivelmente um dos melhores livros de Eagleton e um dos mais interessantes estudos acerca dos temas tratados na obra de Walter Benjamin, o longo en- 
saio Walter Benjamin, or Towards a Revolutionary Criticism (1981) é um divisor de águas. Nele estão presentes valiosas reflexões sobre o universo acadêmico que passava a assimilar com voracidade facetas do pensamento de Benjamin, ao mesmo tempo em que demonstrava reservas em relação ao marxismo por ele professado. Aqui são registradas, como num sismófrago, as movimentações que anunciavam a derrota de muitas lutas políticas e a consequente acomodação do pensamento teórico aos novos tempos. Dialogando primordialmente com o pós-estruturalismo, Eagleton procura ressaltar o processo que está em jogo, ou seja, uma certa higienização feita na obra benjaminiana para que essa se torne mais palatável e dócil frente aos impulsos reformistas das novas vogas téoricas. Assim, colocando em xeque a tradicional divisão do trabalho intelectual, reflexo apequenado da divisão social do trabalho, Walter Benjamin é o livro que a um só tempo une as qualidades do ensaio de fôlego e do manifesto político, mesmo que esses dois gêneros não costumem ser colocados lado a lado de maneira pacífica no julgamento da crítica.

O livro está organizado como um conjunto de ensaios que visitam alguns dos mais importantes debates referentes ao materialismo histórico, mas tendo como veio central as estratégias prioritárias a serem adotadas pela crítica que deseja para si uma postura socialmente engajada e politicamente atuante. Como o próprio Eagleton destaca, é um trabalho que reflete as contradições de um período de crise global do capitalismo e de impasses nas correntes progressistas que almejavam uma efetiva transformação social. É patente, ao longo do livro, o apelo por uma capacidade mais ampla de atuação crítica. Isso aconteceria primordialmente por uma expansão da análise para além das questões puramente textuais ou conceituais, sendo cada vez mais necessário atentar aos aspectos relativos à própria produção cultural e ao uso político dos artefatos culturais. Em virtude disso, o livro não se concentra tanto na obra de Walter Benjamin como foco principal, mas a considera como um ponto de referência para considerações sobre o papel e a função da crítica socialmente engajada.

Aquilo que é especialmente interessante nos ensaios de Benjamin - e que possivelmente influenciou a própria produção de Eagleton - é o modo como é realizada uma combinação dinâmica de crítica cultural, materialismo histórico e pensamento judaico messiânico. Acresce ainda que, na visão de Benjamin, a produção material da arte também deve ser inserida nos elementos para sua explicação. É dessa forma que as interpretações de cunho idealista podem ser 
corrigidas e aprimoradas. O objetivo é evitar soluções que naturalizam as formas de produção artística e de reflexão sobre os artefatos artísticos, ou seja, como se a obra de arte existisse num espaço indeterminado e acima das injunções históricas. Essa abordagem de Benjamin decorre evidentemente de uma das mais célebres de suas proposições: a de que devemos escovar a história a contrapelo, indo na contracorrente de juízos e conceitos enrijecidos, parciais e que quase sempre trazem somente a perspectiva dos vencedores. A motivação disso, desse novo olhar para a história, é elevar para o primeiro plano da análise os resíduos e as ruínas normalmente encobertos pelo pensamento hegemônico. Nesse sentindo, a obra de Benjamin serviu como uma bússola para a obra de Eagleton: uma crítica que pode e deve recuperar elementos esquecidos ou mesmo hegemonicamente neutralizados, mas que, se lidos na contracorrente, podem ser utilizados em prol da transformação social consequente.

Outra faceta da obra de Benjamin destacada por Eagleton é a capacidade que ela tem de prefigurar debates que fariam parte da arena crítica nas últimas décadas do século vinte. A reflexão de Benjamin, que não respeita a rígida divisão entre disciplinas e campos do conhecimento, destrói limites e fronteiras, fazendo com que o trânsito entre diferentes áreas e enfoques críticos sirva de impulso para a intervenção prática e teórica. Os textos do autor alemão anteciparam características que mais tarde seriam utilizados na profusão de abordagens interpretativas do final do século. Várias formas de psicanálise, de teorias linguísticas, da chamada desconstrução, das teorias sobre as vanguardas e ainda sobre o marxismo mereceram, em maior ou menor grau, a atenção de Benjamin. Exatamente por isso, Eagleton observa tal obra como uma possibilidade de manifestação e de ação na conjuntura contemporânea. Não porque ela seja um manancial de respostas prontas ou acabadas, o que seria uma traição à própria postura intelectual de Benjamin, mas sim em virtude da riqueza com que ela capta profundas tendências histórico-sociais. Assim, o livro sobre Benjamin em nenhum momento defende a ideia de que devamos procurar receitas ou métodos fechados. Mais importante do que uma hipotética síntese nitidamente organizada, seria fundamental perceber de que modo diferentes posições teóricas são moldadas, interagem e entram em conflito, sempre dentro de um contexto de preocupações com a atuação prática, de intervenção social. Essa dimensão, da gênese e desenvolvimento das teorias e de sua interconexão com a prática social, será fundamental para os posteriores livros de Eagleton. 
Nesse breve esboço, acompanhando pouco mais do que a primeira década de atividade de Eagleton, podemos observar algumas das principais vertentes que serão determinantes na apreciação de sua obra como um todo. Se estivermos certos em nossa leitura, a obra de Eagleton apresenta uma certa coerência interna, em que vários temas são esboçados e retrabalhados, aparecem e ressurgem em diferentes momentos, além de possibilitarem um diálogo com outras obras literárias, culturais e ensaísticas que, em maior ou menor grau, poderiam ser agrupadas em torno de uma tônica comum ao longo dos últimos cinquenta anos: a trajetória do pensamento crítico vista a partir do modo como este responde às mudanças históricas e sociais.

Certa audácia e amor à polêmica têm marcado o caminho das intervenções teóricas de Terry Eagleton. Mas muito da incompreensão gerada possivelmente advém do fato de que seus textos não são entendidos a partir daquilo que se propõem a ser desde o início, ou seja, ensaios de intervenção, que carregam a marca de não respeitarem as rígidas divisões entre disciplinas e de muitas vezes terem como um de seus principais impulsos exatamente a denúncia mesma de tais divisões. Desse modo, um comentário literário muda rapidamente para uma referência filosófica, para imediatamente arriscar uma conclusão política e uma investigação das motivações materiais que emolduram todo o quadro. Contudo, tais operações não raro são vistas mais como ecletismo excessivo do que como tentativa de compreensão de uma conjuntura a partir de vários prismas - e esse tipo de juízo crítico, tanto à direita quanto à esquerda, já é em si mesmo um sinal da compartimentação no pensamento teórico produzido nos últimos cinquenta anos.

Grande parte do impacto das ideias de Eagleton decorre do fato de, em inúmeros momentos, elas tomarem como ponto de partida a própria investigação das origens e da constituição dos estudos literários. Para estudantes, professores e demais interessados em literatura e cultura, o esforço de contextualização histórica realizado por Eagleton pode representar a oportunidade de desfazer alguns mitos, criticar alguns tabus e reforçar outros pontos de vista dissonantes. Aliado a esse ímpeto, os escritos de Eagleton fazem um constante chamado sobre qual é a "função da crítica". Sua visão não deixa dúvidas: uma crítica que seja feita para alimentar o atual estado de coisas, talvez não mereça ser reconhecida como tal. O verdadeiro pensamento crítico apenas tem alguma esperança de relevância a partir do momento em que ousar observar a história a contrapelo 
e fazer da divulgação dessa observação uma das razões de sua existência. E é nesse sentido que Eagleton construiu um estilo bastante peculiar: suas obras são quase todas, desde o nascedouro, obras de divulgação, numa escrita fluida, que quebra a barreira entre escrita criativa e teórica, ao mesmo tempo em que faz da ironia e do humor armas poderosas que auxiliam o diálogo com o leitor. Trata-se de uma prosa crítica que procura abarcar as contradições socias e culturais, comumente colocando lado a lado campos do conhecimento e linhas argumentativas aparentemente distantes e díspares, mas que, quando em contato, produzem novas perspectivas. $\mathrm{O}$ olhar atento ao contraditório, para aquilo que está velado pelas aparências, bem como a busca pela lógica interna que perpassa diferentes linhas interpretativas: tudo isso não ocorre como simples demonstração de destreza estilística por parte de Eagleton, mas sim a partir de uma necessidade de responder aos conflitos e injustiças das sociedades movidas pelos antagonismos de classe.

Como últimas observações, e levando em consideração o que expusemos no tocante aos seus primeiros livros, julgamos relevante destacar que a obra de Eagleton tem alguns pontos que nos parecem fundamentais: ela critica os conceitos dominantes sobre o que é a literatura; faz com que os textos literários retornem ao campo das práticas sociais; questiona juízos estabelecidos e a recepção em relação a autores e obras importantes; e, por fim, procura realizar uma prática crítica que tenha ao menos a ambição de interfeir em contextos institucionais e políticos mais amplos, sempre em diálogo com diferentes escolas teóricas. Dessa forma, Eagleton realiza em cada uma dessas intervenções algo que vai além do simples encontro com diversas teorias. Ao explicá-las, imediatamente adiciona novos componentes, renovando a percepção a respeito delas e tendo sempre como meta a crítica integradora: uma crítica que unifica aspectos estéticos, históricos e políticos. 


\section{Referências}

ANDERSON, Perry. The Origins of Postmodernity. London: Verso, 1998.

BENJAMIN, Walter. Understanding Brecht. London: New Left Books, 1973. . Obras Escolhidas I. São Paulo: Brasiliense, 1996. . Illuminations. New York : Schocken Books, 1969. . The arcades project. Cambridge: Belknap Press, 1999.

EAGLETON, Terry. Shakespeare and Society. London: Chatto \& Windus, 1967. . The Body as Language. London: Sheed \& Ward, 1970. . Exiles and Émigrés: Studies in Modern Literature. London: Chatto \&

Windus, 1970. millan, 1975. . Myths of Power: A Marxist Study of the Brontës. London: Mac. Criticism and Ideology. London: New Left Books, 1976. . Marxism and Literary Criticism. London: Methuen, 1976. .Walter Benjamin, or Towards a Revolutionary Criticism. London:

Verso, 1981.

EAGLETON, Terry. e BEAUMONT, Matthew. A Tarefa do Crítico - diálogos com Terry Eagleton. São Paulo: Editora Unesp, 2010.

REGAN, Stephen (ed). The Eagleton Reader. Oxford: Blackwell, 1998. 